defect when antibodies to purified human muscarinic receptors become available. With these techniques it may be possible to define more precisely the lesion in cases of idiopathic intestinal pseudo-obstruction and other smooth-muscle disorders. If immunosuppression or other treatment proved effective then death, which so often eventually follows the diagnosis of idiopathic intestinal pseudo-obstruction, might also be prevented.

We thank Dr J G Walker for helpful advice and Mrs P Barker for skilled technical help.

\author{
References \\ ${ }^{1}$ Bannister R. Chronic autonomic failure with postural hypotension. \\ Lancet 1979 ;ii:404-6. \\ ${ }^{2}$ Hopkins A, Neville B, Bannister R. Autonomic neuropathy of acute \\ onset. Lancet $1974 ; \mathrm{i}: 769-71$. \\ ${ }^{3}$ Harik SI, Ghandour MH, Farah FS, Afifi AK. Post-ganglionic cholinergic \\ dysautonomia. Ann Neurol 1977; :393-6. \\ 4 Anonymous. Intestinal pseudo-obstruction. Lancet 1979;i:535-6.
}

5 Bannister R, Sever P, Gross M. Cardiovascular reflexes and biochemical responses in progressive autonomic failure. Brain 1977;100:327-44.

6 Bannister R, Davies B, Holly E, Rosenthal T, Sever P. Defective cardiovascular reflexes and supersensitivity to sympathomimetic drugs in autonomic failure. Brain 1979;102:163-76.

7 Smith B. The pathology of the alimentary tract. London: Arnold, 1972.

${ }^{8}$ Dyer NH, Dawson AM, Smith BF, Todd IP. Obstruction of bowel due to lesion in the myenteric plexus. $\mathrm{Br}$ Med $\mathcal{f} 1969 ; \mathrm{i}: 686-9$.

- Sullivan MA, Snape WJ Jr, Matarazzo SA, Petrokubi RJ, Jefferies G, Cohen S. Gastrointestinal myoelectrical activity in idiopathic intestinal pseudo-obstruction. N Engl f Med 1977;297:233-7.

10 Faulk DL, Anuras S, Christensen J. Chronic intestinal pseudo-obstruction. Gastroenterology 1978;74:922-31.

${ }^{11}$ Lewis TD, Daniel EE, Sarna SK, Waterfall WE, Marzio L. Idiopathic intestinal pseudo-obstruction. Gastroenterology 1977;74:107-11.

12 Faulk DL, Anuras S, Gardner GD, Mitros FA, Summers RW, Christensen J. A familial visceral myopathy. Ann Intern Med 1978;89:600-6.

${ }^{13}$ Schuffler MD, Low MC, Bill AM. Studies of idiopathic intestinal pseudoobstruction. I. Hereditary hollow visceral myopathy; clinical and pathological studies. Gastroenterology 1977;73:327-38.

14 Schuffler MD, Pope CE. Studies of idiopathic intestinal pseudo-obstruction. II. Hereditary hollow visceral myopathy; family studies. Gastroenterology 1977;73:339-44.

15 Bolton TB. Cholinergic mechanisms in smooth muscle. Br Med Bull $1979 ; 35: 275-83$.

(Accepted 15 Fanuary 1981)

\title{
Do colonic bacteria contribute to cholesterol gall-stone formation? Effects of lactulose on bile
}

\author{
J R THORNTON, K W HEATON
}

\begin{abstract}
Ten healthy middle-aged women volunteered for a study to test the effect of lactulose- a synthetic, non-absorbable disaccharide-on the colonic metabolism of bile acids and on bile lipid composition. Lactulose ( $60 \mathrm{~g}$ daily in eight cases, $39 \mathrm{~g}$ daily in two) was taken as a proprietary syrup for six weeks, and bile was collected by duodenal intubation before and immediately after the six weeks.

All subjects showed a fall in the percentage of the 7-alpha-dehydroxylated bile acid deoxycholic acid (mean $28.4 \pm$ SEM 3.7 to $15.6 \pm 2.4 ; p<0.002)$ and $a$ rise in the percentage of the primary bile acid chenodeoxycholic acid (mean $33.2 \pm 3.2$ to $42.9 \pm 2.9 ; p<0.001$ ). The percentage of cholic acid rose in eight subjects but mean values did not differ significantly. Bile was initially supersaturated with cholesterol in most subjects and became less saturated with cholesterol in all but one (mean saturation index $1 \cdot 40 \pm 0.11$ to $1 \cdot 19 \pm 0.07 ; p<0.005$ ).

These data support the theory that colonic bacteria contribute to cholesterol gall-stone formation.
\end{abstract}

\section{Introduction}

Bile acids which escape reabsorption in the terminal ileum pass into the colon. There, bacterial $7 \alpha$-dehydroxylation converts primary bile acids into the secondary forms, cholic acid becoming deoxycholic acid, chenodeoxycholic acid becoming

\footnotetext{
University Department of Medicine, Bristol Royal Infirmary, Bristol BS2 8HW

J R THORNTON, MB, MRCP, registrar

$\mathrm{K}$ W HEATON, MD, FRCP, reader
}

lithocholic acid. These secondary bile acids are partially absorbed and enter the bile acid pool. Feeding small amounts of deoxycholic acid reportedly raised bile cholesterol saturation, leading to the suggestion that increased return of deoxycholic acid to the liver alters its metabolism to favour the secretion of bile supersaturated with cholesterol ${ }^{1}$ and hence apt to precipitate cholesterol gall stones. Feeding larger amounts of deoxycholic acid, however, did not produce this effect. ${ }^{2-4}$ Administration of metronidazole, an antimicrobial agent active against many colonic bacteria, reduced the proportion of deoxycholic acid in bile, raised that of chenodeoxycholic acid, and lowered bile cholesterol saturation. ${ }^{5}$

In vitro, $7 \alpha$-dehydroxylation of bile acids is inhibited below $\mathrm{pH}$ 6.0-6.5.6-8 Lactulose, a synthetic, non-absorbable disaccharide, is metabolised to organic acids by the colonic flora and reduces the $\mathrm{pH}$ in the right colon to less than $5 \cdot 0 .{ }^{\circ}$ We therefore predicted that lactulose would reduce $7 \alpha$-dehydroxylation. To test this hypothesis and look for associated improvement in bile cholesterol saturation we have analysed bile before and after administration of lactulose.

\section{Subjects and methods}

Ten apparently healthy women aged $42-51$ years (mean 46) volunteered for the study. Their mean body weight was $118 \%$ of ideal (range 104-135\%). Six subjects were chosen as being known from other studies to have bile supersaturated with cholesterol. For ethical reasons oral cholecystograms were not performed, but no subject had symptoms of gall-bladder disease. As some subjects had highly supersaturated bile, however, a few may have had asymptomatic gall stones. Standard liver function values were normal, and no subject was taking any medication, including oral contraceptives. Subjects maintained their usual diet and activities throughout the study and kept a daily record of bowel movements.

The women were given a proprietary syrup containing $670 \mathrm{~g}$ lactulose, $60 \mathrm{~g}$ lactose, and $110 \mathrm{~g}$ galactose per 1$)$. They were instructed 
to take $15 \mathrm{ml}$ three times daily with meals for one week and then to increase each dose to $30 \mathrm{ml}$, giving a daily dose of $60 \mathrm{~g}$ lactulose, for a further five weeks. Bile was collected by duodenal intubation before and immediately after the six weeks of lactulose administration. After an overnight fast duodenal contents were aspirated following gallbladder stimulation with cholecystokinin. This evoked a prompt flow of more-concentrated bile (total lipid concentration $18-98 \mathrm{mmol} / \mathrm{l}$, median $54 \mathrm{mmol} / \mathrm{l}$ ). Samples obtained in this way have a lipid composition which accurately reflects that of gall-bladder contents ${ }^{10}$

Both bile samples from each subject were analysed in the same batch. Concentrations of total bile salts, phospholipids, and cholesterol ${ }^{11}$ were used to calculate a cholesterol saturation index using the criteria of Hegardt and Dam. ${ }^{12}$ The individual bile acid composition was determined by gas-liquid chromatography. The statistical significance of differences was calculated by Student's $t$ test.

\section{Results}

After taking lactulose the mean percentage of deoxycholic acid in bile decreased from $28.4 \pm$ SEM 3.7 to $15.6 \pm 2.4(p<0.002)$. This fall occurred in all 10 subjects (fig 1 ). Conversely, all subjects showed a rise

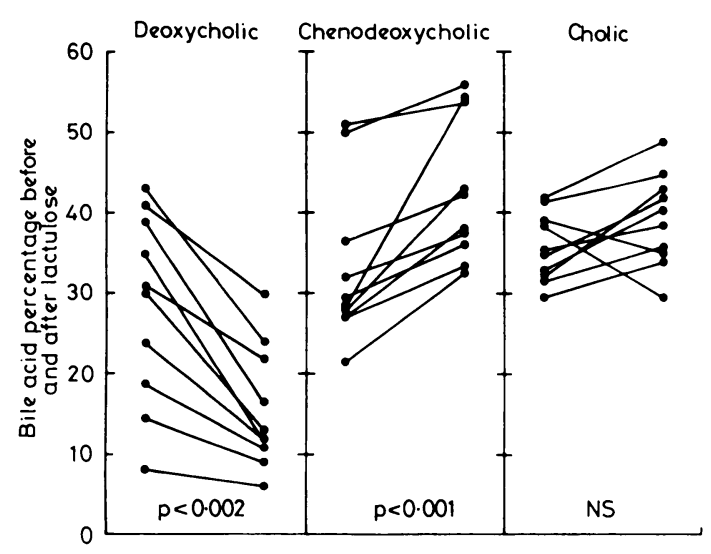

FIG 1-Effect of lactulose administration on biliary percentages of deoxycholic acid, chenodeoxycholic acid, and cholic acid.

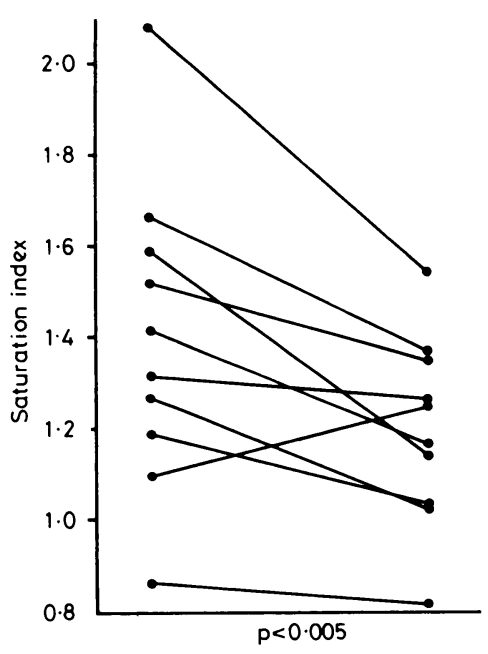

FIG 2-Effect of lactulose administration on bile cholesterol saturation index.

in the percentage of chenodeoxycholic acid $(33 \cdot 2 \pm 3 \cdot 2$ to $42 \cdot 9 \pm 2 \cdot 9$; $\mathrm{p}<0.001)$. The percentage of cholic acid rose in eight subjects but the mean values of $36.0 \pm 1.4$ and $39.0 \pm 1 \cdot 3$ were not significantly different (fig 1). Lithocholic acid was present in trace amounts before and after lactulose $(2 \cdot 5 \pm 0 \cdot 2$ on both occasions).

Bile became less saturated with cholesterol in nine subjects (fig 2). Mean saturation index fell from $1.40 \pm 0.11$ to $1 \cdot 19 \pm 0.07(\mathrm{p}<0.005)$.
The table shows the mean molar percentages of total bile acids, phospholipids, and cholesterol before and after lactulose.

Mean bowel frequency increased from $8 \pm 2$ to $14 \pm 3$ weekly. Two subjects tolerated only $20 \mathrm{ml}(13 \mathrm{~g})$ lactulose thrice daily but the other eight took the full dose without diarrhoea. There was no significant change in mean body weight $(67 \pm 3$ to $66 \pm 3 \mathrm{~kg})$.

Mean molar percentages ( $\pm S E M$ ) of total bile acids, phospholipids, and cholesterol before and after lactulose

\begin{tabular}{lccc}
\hline & Total bile acids & Phospholipids & Cholesterol \\
\hline Before lactulose & $74.1 \pm 1.3$ & $18.1 \pm 1.0$ & $8.3 \pm 0.8$ \\
After lactulose & $76.0 \pm 1.0$ & $17.5 \pm 0.5$ & $6.9 \pm 0.5$ \\
Significance & NS & NS & p $<0.02$ \\
\hline
\end{tabular}

NS $=$ Not significant.

\section{Discussion}

This study shows that administration of lactulose can lower the cholesterol saturation of bile. The mechanism of the reduction is not disclosed by our data. It may be due to reduced cholesterol secretion or expansion of the bile acid pool, or both. Possibly it is linked with the increased proportion of biliary chenodeoxycholic acid, since administration of this bile acid lowers bile cholesterol saturation. ${ }^{13}$ The simplest explanation for the rise in chenodeoxycholic acid is improved intestinal conservation because of reduced $7 \alpha$-dehydroxylation to lithocholic acid -a rapidly excreted bile acid. Nevertheless, the proportion of the other primary bile acid, cholic acid, did not rise significantly. Thus our results are also compatible with the suggestion ${ }^{14}$ that deoxycholic acid selectively inhibits the hepatic synthesis of chenodeoxycholic acid, reduced production or absorption of deoxycholic acid during lactulose administration allowing the liver to produce more chenodeoxycholic acid. As we measured percentages rather than pool sizes of the individual bile acids, however, the absolute amount of their change with administration of lactulose remains uncertain.

The reduction in deoxycholic acid seen in all subjects has several possible explanations. In view of its laxative properties lactulose may accelerate colonic transit, so reducing the time available for the formation or absorption of secondary bile acids. Alternatively, acidification of the colon may increase bile acid excretion, either by precipitation ${ }^{15}$ or by promoting the binding of bile acids to lignin, a component of dietary fibre. ${ }^{16}$ The data, however, are consistent with our hypothesis that, by acidifying the colon, lactulose reduces bacterial $7 \alpha$-dehydroxylation of bile acids.

The effects of lactulose on bile resemble those of wheat bran. Like lactulose, bran lowers biliary deoxycholic acid, increases chenodeoxycholic acid, and can lower cholesterol saturation. ${ }^{17}$ The mechanism of action of bran has not been elucidated. Nevertheless, bran is partly metabolised by colonic bacteria to short-chain fatty acids, ${ }^{18}$ and we suggest that colonic acidification and consequent reduction of bile acid $7 \alpha$-dehydroxylation may partly explain its action on bile.

The clinical relevance of our findings is uncertain. To dissolve existing gall stones probably requires that saturation index be reduced to less than $1 \cdot 0 .^{19}$ This did not occur in this study. Nevertheless, a greater effect may, perhaps, be obtained with more-prolonged administration of lactulose. The relatively modest fall in saturation index seen in this study could be useful in reducing the risk of cholesterol gall-stone formation in highrisk groups or in reducing the possibility of recurrence of gall stones after dissolution by other means.

In conclusion, our findings support the concept that colonic bacterial metabolism of bile acids plays a part in the production of bile supersaturated with cholesterol and hence cholesterol gall-stone formation.

We thank Duphar Laboratories Ltd for providing lactulose syrup. Requests for reprints should be addressed to JRT. 


\section{References}

${ }^{1}$ Low-Beer TS, Pomare EW. Can colonic bacterial metabolites predispose to cholesterol gallstones? $\mathrm{Br} \mathrm{Med} \mathcal{F} 1975 ; \mathrm{i}: 438-40$

2 LaRusso NF, Szczepanik PA, Hofmann AF. Effect of deoxycholic acid ingestion on bile acid metabolism and biliary lipid secretion in normal subjects. Gastroenterology 1977;72:132-40.

${ }^{3}$ Ahlberg J, Angelin B, Einarrson K, Hellstrom K, Leijd B. Influence of deoxycholic acid on biliary lipids in man. Clinical Science and Molecular Medicine 1977;53:249-56.

${ }^{4}$ Carulli N, Ponz de Leon M, Zirori F, Iori R, Loria P. Bile acid feeding and hepatic sterol metabolism: effect of deoxycholic acid. Gastroenterology 1980;79:637-41.

5 Low-Beer TS, Nutter S. Colonic bacterial activity, biliary cholesterol saturation and pathogenesis of gallstones. Lancet 1978;ii:1063-5.

- Midtvedt T, Norman A. Parameters in $7 \alpha$-dehydroxylation of bile acids by anaerobic lactobacilli. Acta Pathol Microbiol Scand 1968;72:313-29.

${ }^{7}$ Aries V, Hill MJ. Degradation of steroids by intestinal bacteria II. Biochim Biophys Acta 1970;202:535-43.

${ }^{8}$ MacDonald IA, Singh G, Mahony DE, Meier CE. Effect of pH on bile salt degradation by mixed fecal cultures. Steroids $1978 ; 32: 245-56$.

- Bown RL, Gibson JA, Sladen GE, Hicks B, Dawson AM. Effects of lactulose and other laxatives on ileal and colonic $\mathrm{pH}$ as measured by a radiotelemetry device. Gut $1974 ; 15: 999-1004$.

10 Vlahcevic ZR, Bell CC, Juttijudata P, Swell L. Bile-rich duodenal fluid as an indicator of biliary lipid composition and its applicability to detection of lithogenic bile. Am $\mathcal{F}$ Dig Dis $1971 ; 16: 797-802$.
${ }^{11}$ Bolton CH, Low-Beer TS, Pomare EW, Wicks ACB, Yeates J, Heaton KW. A simplified procedure for the analysis of cholesterol, phospholipids and bile salts in human bile. Clin Chim Acta 1978;83:177-81.

12 Hegardt FG, Dam H. The solubility of cholesterol in aqueous solutions of bile salts and lecithin. $Z$ Ernachrungswiss 1971;10:223-33.

13 Andersen JM. Chenodeoxycholic acid desaturates bile-but how? Gastroenterology 1979;77:1146-51.

${ }^{14}$ Pomare EW, Low-Beer TS. The selective inhibition of chenodeoxycholate synthesis by cholate metabolites in man. Clinical Science and Molecular Medicine 1975; 48:315-21.

${ }^{15}$ Igimi H, Carey MC. pH-solubility relations of chenodeoxycholic and ursodeoxycholic acids: physical-chemical basis for dissimilar solution and membrane phenomena. 7 Lipid Res 1980;21:72-90.

${ }^{16}$ Eastwood MA, Hamilton D. Studies on the adsorption of bile salts to nonabsorbed components of diet. Biochim Biophys Acta 1968;152:165-73.

17 Pomare EW, Heton KW, Low-Beer TS, Espiner HJ. The effect of whea bran upon bile salt metabolism and upon the lipid composition of bile in gallstone patients. Am $\mathcal{F}$ Dig Dis 1976;21:521-6.

18 Cummings JH, Hill MJ, Jenkins DJA, Pearson JR, Wiggins HS. Changes in fecal composition and colonic function due to cereal fiber. Am $\mathcal{F}$ Clin Nutr 1976;29:1468-73.

19 Dowling RH. Chenodeoxycholic acid therapy of gallstones. In: Paumgartner $\mathrm{G}$, ed. Clinics in gastroenterology. Bile acids. London: W B Saunders Ltd, 1977:141-63.

(Accepted 15 Fanuary 1981)

\title{
Diagnosis of deep vein thrombosis using autologous indium-III-labelled platelets
}

\author{
ALBERT FENECH, J K HUSSEY, F W SMITH, P P DENDY, B BENNETT, A S DOUGLAS
}

\begin{abstract}
Forty-eight patients who had undergone surgical reduction of a fractured neck of femur or in whom deep vein thrombosis was suspected clinically were studied by ascending phlebography and imaging after injection of autologous indium-111-labelled platelets to assess the accuracy and value of the radioisotopic technique in diagnosing deep vein thrombosis. Imaging was performed with a wide-field gammacamera linked with data display facilities. Phlebography showed thrombi in 26 out of 54 limbs examined and a thrombus in the inferior vena cava of one patient; imaging the labelled platelets showed the thrombi in 24 of the 26 limbs and the thrombus in the inferior vena cava.

The accumulation of indium-111 at sites corresponding to those at which venous thrombi have been shown phlebographically indicates that this radioisotopic technique is a useful addition to methods already available for the detection of deep vein thrombosis.
\end{abstract}

University of Aberdeen, Foresterhill, Aberdeen AB9 2ZD ALBERT FENECH, MD, MRCP, lecturer in medicine

J K HUSSEY, MB, DMRD, senior registrar, department of radiology F W SMITH, MB, FFR, consultant, department of nuclear medicine $P$ P DENDY, PHD, reader, department of biomedical physics and bioengineering

B BENNETT, MRCP, MRCPATH, senior lecturer in medicine

A S DOUGLAS, FRCP, FRCPATH, regius professor of medicine

\section{Introduction}

The diagnosis of deep vein thrombosis on the basis of clinical signs is difficult and frequently incorrect, ${ }^{1-3}$ with the exception of phlegmasia dolens, when the clinical features are reliable indicators. ${ }^{4}$ Most deep vein thrombi, however, are less extensive and thus present fewer clear-cut clinical features than phlegmasia, though they still carry the risk of major pulmonary embolism. This risk necessitates objective confirmation of a clinical suspicion of deep vein thrombosis, and various methods have been used for this including ascending phlebography, detection of Doppler flow, impedance plethysmography, thermography, and radioisotopic techniques ( ${ }^{125}$ I-fibrinogen, ${ }^{123} \mathrm{I}$-fibrinogen, ${ }^{99 \mathrm{~m}} \mathrm{Tc}$-macroaggregated albumin, ${ }^{99 \mathrm{~m}} \mathrm{Tc}$ urokinase, and ${ }^{99 \mathrm{~m}} \mathrm{Tc}$-plasminogen). Unfortunately, all these methods have drawbacks limiting their use. ${ }^{4}$ An ideal diagnostic technique must be painless; non-invasive; safe and free from side effects; simple and reliable; rapid; accurate in detecting the site, size, and number of thrombi, whether recent or old; repeatable; financially acceptable; and require minimal transportation of the patient. No method currently satisfies these criteria, and new methods require to be established and examined.

We describe a simple, rapid technique for labelling autologous human platelets with indium-111 and imaging with a gammacamera to detect deep vein thrombosis and compare the accuracy of this method with that of ascending phlebography.

\section{Materials, methods, and patients}

Autologous platelets were labelled by using the technique developed by Hawker et al. ${ }^{6}$ This entailed removing $26 \mathrm{ml}$ of blood and separating the platelets, which were labelled with $180-220 \mu \mathrm{Ci}$ of indium-111 oxine (Radiochemical Centre) and reinjected within 45 minutes of 